\title{
THE PACTUM MODEL: PRODUCT ANALYSIS OF COST AND TIME USING MATHEMATICS
}

\author{
D J EASTERS \\ Department of Fashion Management, Marketing \& \\ Communication, School of Art \& Design, Nottingham Trent \\ University, Nottingham, NG1 4BU, UK \\ dj@fashioneasters.com
}

\begin{abstract}
Establishing a mathematical supply-chain model is a proposition that has received attention due to its inherent benefits of evolving global supply-chain efficiencies. This paper discusses the prevailing relationships found within apparel supply-chain environments, and contemplates the complex issues indicated for constituting a mathematical model. Principal results identified within the data suggest, that the multifarious nature of global supply-chain activities require a degree of simplification in order to fully dilate the necessary factors which affect, each sub-section of the chain. Subsequently, the research findings allowed the division of supplychain components into sub-sections, which amassed a coherent method of product development activity. Concurrently, the supply-chain model was found to allow systematic mathematical formulae analysis, of cost and time, within the multiple contexts of each sub-section encountered. The paper indicates the supply-chain model structure, the mathematics, and considers how product analysis of cost and time can improve the comprehension of product lifecycle management
\end{abstract}

Keywords: Fashion; supply-chain; mathematics

\section{Introduction \& Background}

Since $1990^{1}$ evolving global supply-chain efficiencies has become a key driver in the race for retail prominence ${ }^{2}$; this notion was highlighted by Ref. 3, who said "modern competition has shifted from company vs Company, to supply-chain vs supply-chain”. Recent global retail players ${ }^{2}$ have shown awardable attributes and have provided other companies with unfathomable judgments on whether to adopt responsive or efficiency supply-chains, when adopting stages for product development processes. ${ }^{4}$ However, found within other current literature, many academics believe that there are a lack of applied strategic perspective on global sourcing ${ }^{5}$ and a lack of performance measuring techniques, ${ }^{6}$ contributing to organisations being unable to fully encompass the analysis of a complete product lifecycle, ${ }^{7}$ throughout its supply-chain conception. ${ }^{8}$

Consequently, academic interest in the increasingly complex fashion supply-chain has grown over the last few decades ${ }^{3}$; due to the fashion industry being of significant economic importance ${ }^{9}$. Retail success has been defined as those organisations which deliver high levels of customer service, with as little inventory as necessary, whilst obtaining the highest gross margins possible, within the defined time frame; however, Ref. 8 further suggest that many organisations endeavor to source globally without completely identifying or underestimating the true costs, ${ }^{5}$ which as a result leads to poor foresight about their sourcing decisions. ${ }^{8}$

Specifically relating to the fashion industry, Ref. 4 identifies that many organisations fail to manage their supply-chains due to an imbalance between strategy and product demand. Fashion products are said to be "innovative products" with high levels of volatility and therefore create unpredictability based on issues such as demand and lifecycle length; despite this if delivered effectively, fashion products can create high gross margins ${ }^{4}$; inevitably all participants within fashion retail strive for the Holy Grail, ${ }^{8}$ i.e. the utopian timely balance of the '4Ps of Marketing' ${ }^{10}$; although most are forced to settle for a reality based on their own firms differential advantages. ${ }^{11}$

Within the competitive fashion environment, retailers are also said to be reducing their supplier portfolios to gain control using performance reviews, ${ }^{3}$ whilst continually struggling to deal with global misunderstandings and misinterpretations when communicating product development processes. ${ }^{12}$ Concurrently, it has been suggested by Ref. 13 that it has become extremely difficult to utilize emerging technologies within simultaneous potential global markets.

Additional concerns from academics, based on fashion sourcing strategies, is the perceived lack of knowledge ${ }^{5}$ concerning specific global supply-chain functionalities, ${ }^{6}$ and the inexperienced understanding of such managerial tactics, when offshore components need to address new multifarious environments and policies. ${ }^{4}$ Although global sourcing is still regarded as being convoluted; Ref. 5 points out that the current state of product development and worldwide retailing, can no longer be seen as an emerging tactic. However, continuing changes in consumer behavior, demographics and manufacturing hubs, has forced some organisations to struggle to keep up with the competitive pressures faced in global sourcing strategies. ${ }^{14}$ Nevertheless, many 
fashion companies are keeping up and are dynamically evolving to become some of the most prolific and successful international retailers. ${ }^{11}$

All being said, strategies that enable a simplification of component parts are considered advantageous ${ }^{12}$; on that account and that of the absent mathematical supply-chain model ${ }^{6}$; it seems appropriate to aim for a suitable solution to this required dimension, of the modern day global supply-chain strategy. It has been suggested that a mathematical model has the ability to reduce $R \& D$ costs whilst speeding up the product development processes; Ref. 15 goes on further to point out that understanding the links within product scenarios, can help identify commercial product opportunities and enable the performance values to be analysed in more depth.

It has therefore, been suggested that there is a current need for the complex supply-chain components to be reconfigured, to allow a more comprehendible and holistic overview of the activities involved. ${ }^{6}$ Consequently, this paper ventures towards a holistic model of the apparel supply-chain, whilst giving a concurrent mathematical algorithm, to enable future performance measures to transmogrify.

\section{Methodology \& Analytical approach}

Due to the differential nature of global fashion supply-chains, the research orientations and methodological approaches were triangulated in order to analyse individual supply-chain sections, rather than trying to represent a singular organisation through a case study. After completing a significant period of active and observational research within respectable global fashion supply-chain organisations, whilst actively undertaking a variety of key industry roles, and completing an extensive literature review; these methods of quantitative and qualitative data collection were enhanced by concentrating on high profile individual sample groups, in order to fulfil four different semi-structured interviews within highly respected corporations; plus, by leading a focus group consisting of five high profile fashion designers'.

Primary data results were audiotape recorded and transcribed, with participant anonymity being protected, to ensure that ethical issues were upheld. To reduce external bias, respondents were not pre-warned of the aggregated questions ${ }^{16}$; allowing answers to be based on their own experiences, underpinning their professional employment activities within the fashion sector.

Although the primary sample size was small, the data sets are considered of high relevance to supply-chain management. In support of the literature findings, the primary qualitative data was quantified using post-coding techniques, which allowed the main issues to be broken down into less complex variances and cross-referenced with current literature. ${ }^{17}$

Therefore, the primary research approach was consistent and systematic throughout, allowing the overall cross-sectional and empirical research design to be valid in its findings. ${ }^{15}$

In addition to the traditional methods of collecting data, it was felt to address such a complex problem, that there needed to be unorthodox methods of analysing the data holistically. For this reason various approaches to data analysis and problem solving were researched; Ref. 18 was found to have conducted an extensive literature review into Six Sigma DMAIC (Define-Measure-Analyse-Improve-Control) general methods for problem solving; which has acquired acclaim for its strong emphasis on statistics, structural method capabilities and ability to break down problems into generic subtasks. Their suggested approaches of definition stream and science research stream problem solving applications, delivered valuable viewpoints when facilitating statistical modelling of cause-and-effect relations. Concurrently, the use of DMAIC within applications of supply-chain management problem solving was said to have a strong incorporation of domain knowledge along with fault knowledge elements. ${ }^{18}$ Domain knowledge diagnosis of the problem was found to be relevant to this study, accompanied with brainstorming, five why's, data mining, cause-and-effect diagrams and exploratory data analysis. $^{18}$

\section{Theoretical PACTUM Model ${ }^{\circ}$ : Incorporated research data and analysis}

From the post-coding analysis conducted on the data sets, significant issues arose from a variety of different processes and classifications, which concern product development cycles, under numerous pretences and industry procedures.

However, adverse effects concluded from the interviews and the focus group, suggested that time, costs and the different interpretations of supply-chain components, still appeared to be the main effects on product development success and competitive advantage. These views were consistent with the literature, with the most notable synergies resulting from the appreciation that the supply-chain performance can be influenced ${ }^{1}$ by three main types of functional classification i.e.: relationships ${ }^{19}$; product type ${ }^{20}$ and market drivers. ${ }^{21}$ The below figures 1-3 show these three main classifications and demonstrate through graphically representation, the variety of connections made when considering the various types of supply-chain operation. 
Although these classifications are from a reliable academic source, there is also potential of an organisation to operate in a way that encompasses some/all of these supply-chain classification approaches concurrently when developing product strategies ${ }^{22}$ :

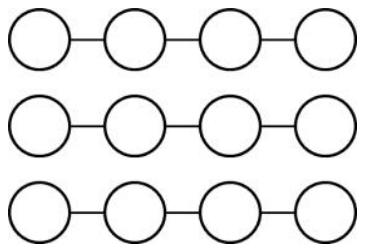

Fig. 1. Completely Disconnected Networks: Supply-chains that operate highly vertically integrated networks, whereby retailer and manufacturer are usual combined (e.g. Spanish retailer Zara).

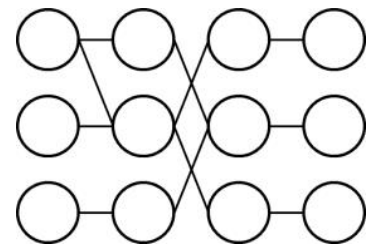

Fig. 2. Partially Overlapping Networks: Supply-chains that operate independen networks that join together for mutua benefit (e.g. Global fashion brand Hugo Boss, being sold through UK retailer John Lewis).

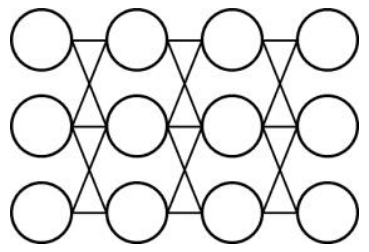

Fig. 3. Completely Overlapping Networks: Supply-chains that operate in multiple networks for the benefit of an own brand retailer or private label-owning corporation (e.g. UK fashion group Pentland Brands Plc.)

Concurrently, the research data signified that there are numerous variables concerning product development processes and that individuals rely heavily on effective communication and correct functionality, throughout each identified stage. Having said that, due to the nature of the global fashion retail industry the identified stages of product development can drastically vary according to individual products, human interaction and organisational structure. This goes someway in highlighting the difficulty of analysing the fashion supply-chain, as recognised by academics and practicing parties. Significantly, the researcher conducting the data collection and analysis had a unique perspective of the supply-chain through their own global buying, manufacturing and problem solving experiences.

As a result, the collected data from the various research samples was converged with the methodical approaches to model formulation outlined by Ref. 15, together with constituents of the Six Sigma DMAIC problem solving practices ${ }^{18}$. This convergence of data and hypotheses gave a clear and systematic approach to the steps needed for the development of such a complex synergy.

Therefore, instead of arranging quotations, graphs and charts as research data, the results from the methodology used in this research is presented in a graphical model simulation. This system of graphical representation of data allowed for the variables to be consolidated and simplified. Research conducted by Ref. 15 suggested that statistical learning techniques are a valuable tool for detecting complex relationships and interaction variables, which was indeed helpful in the mathematical model conception.

These approaches to research data management and data representation enabled the mathematical assessment of effort encountered within the complex fashion supply-chain, which is identified in figures 4-11. Consequently, the 'Product Analysis of Cost \& Time Using Mathematical Modelling' (PACTUM Model $\left.{ }^{\odot}\right)$ method, is supported by the literature, primary data collected and was found to allow systematic mathematical formulae analysis, of cost and time, within the multiple contexts of each supply-chain sub-section encountered. This has then led to a holistic mathematical formula for calculating overall and divisions of effort (using the indexed sub-sections found in section 3.2.9.) whilst analysing each sub-section and/or entirety of a products lifecycle, when considering cost and time as the initial calculating factors.

\subsection{PACTUM Model ${ }^{\circledR}$ mathematical formula}

In order to understand the holistic mathematical model, the below equations describe the sum for calculating the highest value of total supply-chain effort:

3.1.1. Formula $1 \& 2$. The PACTUM $\operatorname{Model}^{\odot}$ allows the calculation of effort $(\boldsymbol{E})$, within each sub-section of the supply-chain to be measured; with the sub-sections of the supply-chain defined as $(\boldsymbol{i})$; costs defined as $(\boldsymbol{c})$; time is defined as $(\boldsymbol{t})$ and the function of these sub-sections defined as $(\boldsymbol{F})$ :

$$
E_{i}=F_{i}\left(c_{i}, t_{i}\right)
$$




$$
E_{i}=F_{i}\left(c_{i}, t_{i}\right)=\frac{1}{\sqrt{c_{i}^{2}+t_{i}^{2}}}
$$

3.1.2. Formula 3. In consideration of the holistic mathematical formula of the PACTUM Model ${ }^{\odot}$; formula 5 below describes how effort can be measured within a single products sub-section lifecycle. The values will ultimately range from high effort to low effort. Plus, these values can be assigned by adding the effort values of each dependent variable within the sub-section, identified in the broad ranging index (section 3.2.9.):

$$
\left(\sum_{i} E_{i}\right)
$$

3.1.3. Formula 4. Significantly by observing the non-assumption that the effort value cannot be equalled too or larger than one; it can be said that $\mathbf{1}$ is the highest effort value achievable. Most importantly, the lowest value assigned can only be determined by the nature of the organisations own differential supply-chain functions which must be defined by the model adopter, according to their own operational cost values, time frames and subsequent effectiveness:

$$
E_{i}=\frac{1}{\sqrt{c_{i}^{2}+t_{i}^{2}}}
$$

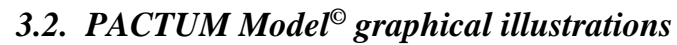

Represented in a simple yet intuitive manner, by figure 4, the entire formation of the PACTUM Model ${ }^{\odot}$ shows the converged attributes, variables and relationships found within global supply-chains and product development process. However, it could be argued that this simplified representation of such complex synergies is lacking more problematical ascendants of current global supply-chain functions. To address this point, it has been

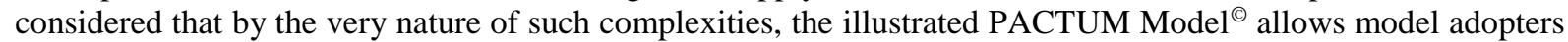
a more fluid approach, to supply-chain analysis, when considering their own differential organisational structures and product development strategies; Hence, allowing the variable supply-chain functions to be customised rather than prescribed.

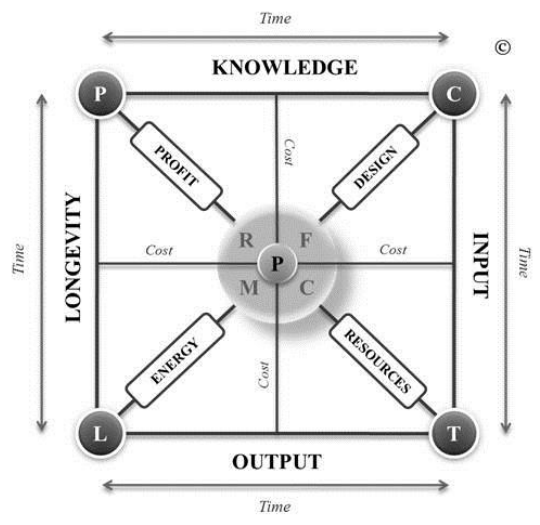

Fig. 4. Holistic overview of PACTUM Model ${ }^{\odot}$. The central point being $(\mathrm{P})$ represents the actual product being developed.

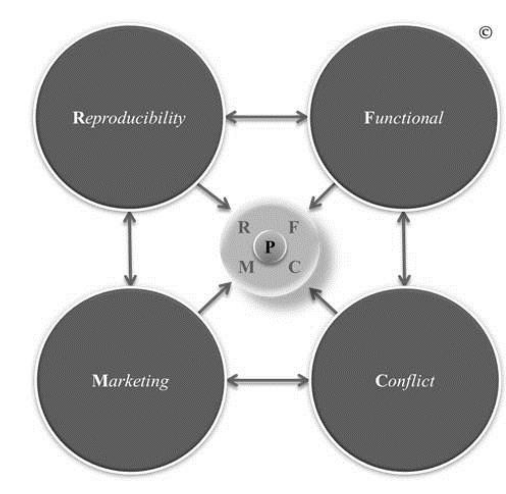

Fig. 5. Illustration showing the four main independent variables of the supply-chain that affect the product during its entire lifecycle.

3.2.1. PACTUM Model ${ }^{\odot}$ : Independent variables. Identified within the in-depth literature review, research methodologies and analytical approach data (represented graphically in figure 5). Were found to be suggestions of a number of independent variables, the networks created by their functions and how these variables affect a product during all stages of its lifecycle. Significantly, the most relevant independent variables were: the actual product $(\mathrm{P})$; the product and brand marketing functions $(\mathrm{M})$; a products ability to be reproduced and replicated using mass or customized manufacturing techniques (R); the functional element of the product itself, as developed by the creator and perceived by the user $(\mathrm{F})$; and the unescapably conflict which occurs during 
product conception, production and completion (C). Consequently, due to these independent variables being independent and variable by their very nature of functional capacity, they are represented only by the typography letters ( $\mathrm{R}, \mathrm{F}, \mathrm{C}$, and $\mathrm{M}$ ) and are centrally placed to form an embryonic-like element around the central product (P). In doing so, these variables are addressed as attributes towards product lifecycle success; although they are not analysed within the mathematical model formation, merely appreciated within the supply-chain processes and subsequent functional variances.

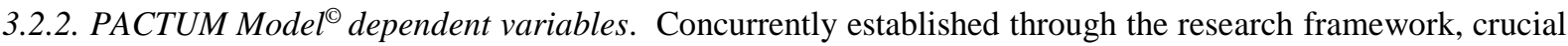
dependent variables were also found to significantly affect a products lifecycle strategy and success.

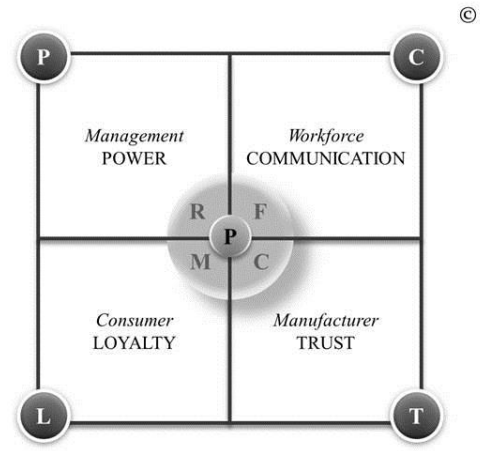

Fig. 6. Illustration showing the four main dependent variables specifically associated with relationships and job functions of the supply-chain that are necessary to produce and sell a product during its lifecycle.

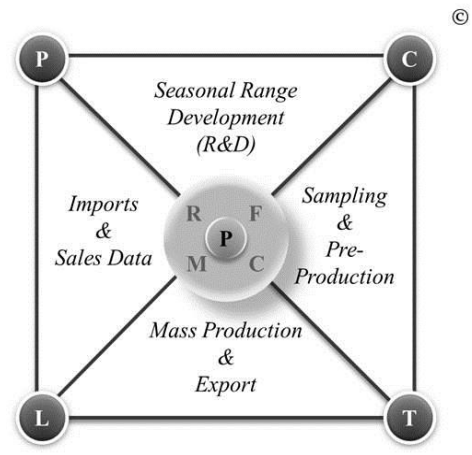

Fig. 7. Illustration showing the four main dependent variables specifically associated with the processes found within the supply-chain that are necessary to produce and sell a product during its lifecycle.

Shown within figure 6, the main dependent variables identified are attributed towards the human elements of supply-chain functional capabilities and therefore represented within four categories; whilst being finally illustrated within the model by the circular corner typographical labels $(\mathrm{P}, \mathrm{C}, \mathrm{T}$, and $\mathrm{L})$. These four categories can be divided further into both the human functions and their contributing human engagement factors that enable these defined human functions to be performed within product lifecycle practices. Thus, the human functional engagement of the management team is to maintain their position of power $(\mathrm{P})$; the human functional engagement of the workforce is to maintain their ability to effectively communicate $(\mathrm{C})$; the human functional engagement of the manufacturer is to maintain their trustworthy status $(\mathrm{T})$; and the human functional engagement of the consumer is to behave accordingly and remain loyal to the product/brand in question (L).

It is recognised that these human functions and their critical success factors are not singular in their activity or supply-chain performance value; therefore, figure 7 represents the other four main dependent variables attributed towards the actual product lifecycle processes themselves. If we consider that figures $6 \& 7$ were laid on top of one another, it would be possible to appreciate that both the management and workforce have elements of human functional capabilities and engagement factor levels within the seasonal range development stages of the products lifecycle; simultaneously the workforce and manufacturer both have elements of human functional capabilities and engagement factor levels within the sampling and pre-production stages; the manufacturer and consumer both have elements of human functional capabilities and engagement factor levels within the mass production and export requirements; and the consumer and the management both have elements of human functional capabilities and engagement factor levels within the import necessity and subsequent sales data.

At this stage it is worth pointing out that all these dependent variables and their human functional capabilities and engagement factor levels, are neither inclusive nor exclusive of each other; thus significantly, such functions should have an ability to flexibly interact within all supply-chain functions concerned, on a required level. That being said, the PACTUM Model ${ }^{\odot}$ illustration of dependent functions (shown in figures $6 \&$ 7) appreciates the nature and variety of supply-chain functions, capabilities, processes, engagement levels, networks and variables created. Yet by addressing these complexities in a researched, experienced and simplified manner; the PACTUM Model $^{\odot}$ is able to uniquely divide the purpose of each supply-chains functional capabilities conducted; allowing an adopter of this model to define their own specific supply-chain practices (by using the suggested index in section 3.2.9. as guidance) and then tailor the functional elements/values of each sub-section, to their own organisational structure and product development strategies. 


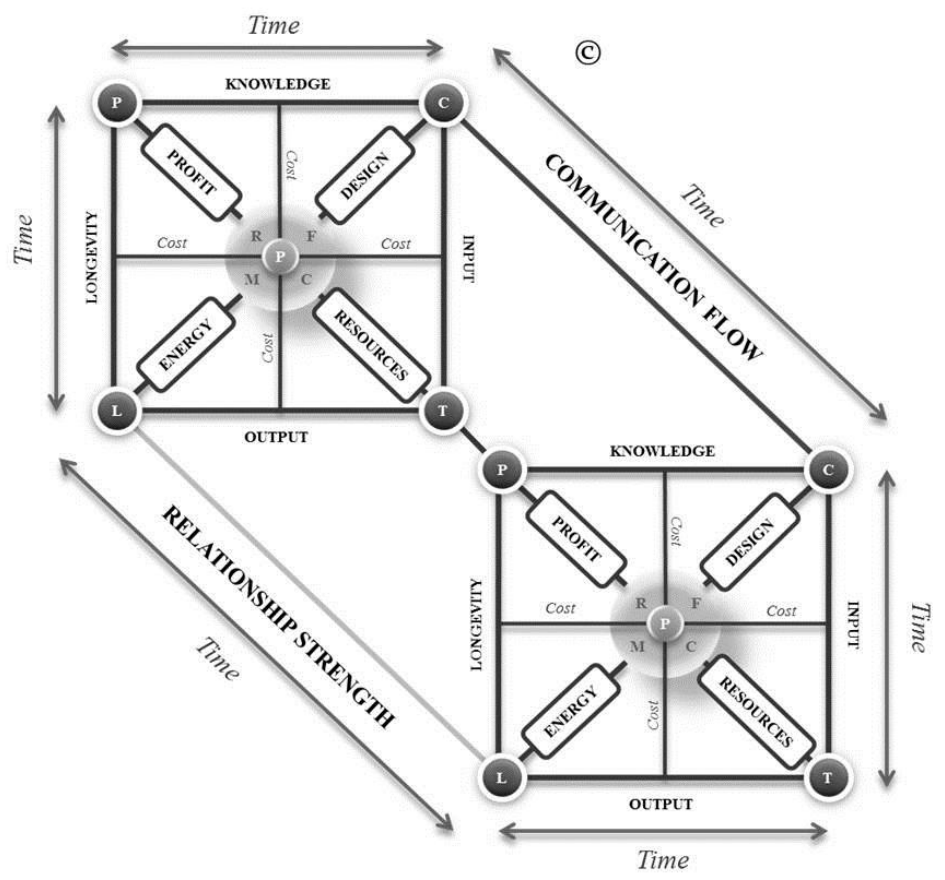

Fig. 8. This illustration shows how the PACTUM Model ${ }^{\odot}$ can be configured to represent a supply-chain of numerous organisational components and demonstrates the relationship of retailer and supplier engagement.

3.2.4. PACTUM Model ${ }^{\odot}$ : Creating extended networks for analytical simulations. The illustration shown in figure 8 demonstrates how the PACTUM Model ${ }^{\odot}$ can be attributed to more than one organization within a defined supply-chain network. Figure 8 shows the top PACTUM Model ${ }^{\odot}$ representing the calculations attributed to Primary Retail organisations and with the bottom PACTUM Model ${ }^{\odot}$ representing calculations attributed to Secondary Supplier organisation. It is possible to extend the PACTUM Model ${ }^{\odot}$ further to include as many organisation elements depending on the nature of a supply-chain construction. The main point to consider here is that the calculations required for the Primary Retail PACTUM Model ${ }^{\odot}$ calculations, when considering the values attributed to the manufacturing sub-sections (indexed in section 3.2.9. as $h$ and $u$ ); can be unreliable depending on the levels of trust within these functional relationships. These indicated areas $(h$ and $u$ ) found within disconnected manufacturing networks, can cause varying degrees of significant conflict when sharing sensitive information; thus creating potential problems in collecting the accurate levels of data needed for the total supplychain effort calculus.

This problematic area of supply-chain connection becomes more apparent when supply-chains consist of disconnected networks, as suggested by Ref. 12 these types of supply-chains are reluctant to share financial data with one another for fear of unbalancing the levels of trust and power that are actively desired within these functional / conflicting relationship scenarios. Additional supply-chain concerns are related to significant negative issues that arise within this area of disconnected networks in manufacture; especially when the Secondary Supplier uses a Third-Party Supplier that has not be recognised or agreed for use by the Primary Retail organisation. A Third-Party Supplier with total disconnection to the Primary Retail organisation, leaves an inability to identify a PACTUM Mode ${ }^{\odot}$ connection to the holistic supply-chain configuration (as illustrated in figure 8) and therefore, as in the model situation it is difficult to analyse their effort values and functional capabilities; which is disappointingly and sometimes disastrously true in the physical sense also.

Alternatively, if the supply-chain encountered is one of a connected network, which demonstrates high levels of communication, information sharing, relationship strength and trust (as shown in figure 8). Then the effort values of the complete supply-chain functions can be analysed right down through the chain; for example: highly connected networks (such as Spanish Retailer Zara) encompass Primary Retail, Primary/Secondary Manufacture, Primary/Secondary Mill House, Primary/Secondary Resources and ultimately the known product origin, all based in a single location or self-controlled supply-chain formations. This formation, may allow Zara easier analysis of their total supply-chain effort, due to the nature of the singular horizontal supply-chain construction.

Simultaneously, there will always be supply-chain networks that consist of completely overlapping, partially overlapping, disconnected networks, or a combination of all these categories. A degree of common sense is 
required when considering how much data will be reasonably collected from each supply-chain connection and this will be dependent on those network communication efficiencies, relationship strengths, trust, loyalty and power balances.

3.2.5. PACTUM Model $^{\odot}$ : Dependent effort functions. Before the explanation of the sub-section index (identified in the following section 3.2.9.) it is essential that the initial holistic graphical model formulation (shown previously as figure 4) be concluded with regard to its final appearance. Discussed and illustrated in the previous sections/figures and identified in simplistic formations, were the main independent and dependent variables to which significant supply-chain functional processes and product lifecycle practices are said to occur. These are now represented by figure 4 within the holistic PACTUM Model ${ }^{\odot}$ which shows all of these variables situated in a semi-invisible format; allowing their direct and indirect importance to influence and sub-section index system.

Additionally, written around the edge (vertically and horizontally) of figure 4 are the dependent effort functions: Knowledge, Input, Output and Longevity. These dependent effort functions are required in order to fulfill the variables outlined in figures 5, 6 and 7.

The Knowledge label therefore, relates specifically to the Management, Power, Workforce, Communication and Seasonal Range Development variables. Noted within the research data was the existence of experienced knowledge, identifiable within these related variables, which seemed to allow an appointed educated success value to the products profitability; plus an experienced knowledge contribution of an organisations practices. Subsequently, this experienced effort function of knowledge help develop the supply-chains human capabilities, effort, engagement and performance undertaking of the variable product lifecycle functions, relating specifically to product lifecycle success.

Similarly written on figure 4 as Input; this label relates specifically to the Workforce, Communication, Manufacturer, Trust, Sampling \& Pre-production variables of product development cycles. Discovered in the research data, input functions are required so that these other attributed variables are effective in their effort function; particularly when concerning product specifications; the input of the right levels of communication and trust between the parties to establish effective relationships; and the input of expertise specific to both the retailer and manufacturer. Significantly, input functions within supply-chain practices are said to be an imperative success/failure variable during product development process. Consequently, this section of the supply-chain has been extensively research and conclusions suggest that the levels of human interaction, capabilities, misunderstanding and misinterpretation of inputted variables; can make or break a supply-chain network and their products success.

Concurrently, the labeled sections associated with Output, are said to be those supply-chain variables relating to Manufacturer, Trust, Consumer, Loyalty, Mass Production \& Exports. Research data identifies that this effort function of output found within supply-chains, are more often, than not, physically uncontrolled by the Primary Retailer; which suggests why retailers conduct increasing levels of manufacturer performance review and consumer behavior analysis, in order to maintain their levels of power over these product lifecycle variables. Noteworthy, is the constant desire of the fashion industry to improve the output quality, reduce the output costs, diversify the output sales channels and by speeding up the production techniques and export channels, so that their consumers can be serviced accordingly; ergo trust their product offering, brand, prices, sales platforms and remain loyal to the supply-chain.

The Longevity label relates specifically to the functions of Consumer, Loyalty, Management, Power, Imports and Sales Data variables. Conceived within this model formulation these variables are both the ending point and starting point for supply-chain and product lifecycle strategy. Hence, if products can be imported efficiently, displayed pleasingly and priced accordingly, then the consumer is more likely to behave as intended and remain loyal and physically contribute to the management's historical sales data (or experienced knowledge) which ultimately provide the organisations profit margins (positively or negatively depending on the supply-chains output variables). By creating products that possess longevity, retailers and brands are more likely to maintain products and supply-chains that create continued consumer desire; which adds to the supply-chains knowledge and sustainable product portfolio.

These sub-sections of functional variables complete and start the continuous supply-chain product lifecycles once more.

3.2.6. PACTUM Model $^{\odot}$ : Core dependent product functions. Shown by figure 4 are the core product functions that all other previously mentioned variables and functions are dependent upon, with these being: Design, Resources, Energy and Profit. These core dependent product functions are placed within the sub-sections of the PACTUM Model ${ }^{\odot}$ that represent their attributed independent and dependent variables and functionalities as 
formerly illustrated and discussed. By placing these core functions along the diagonal axis of the PACTUM $\mathrm{Model}^{\odot}$, it can be easily viewed how they interact with all other variances and should be considered to do just so; simultaneously being affected by the other variables, the positive and negative values felt within the supplychain activities and product lifecycle success levels.

3.2.7. PACTUM Model ${ }^{\odot}$ sub-section index system. The following sections of this paper shows how the PACTUM Model $^{\odot}$ uses graphical representation, of each sub-section, to define the key performance calculations by using a right-angled triangle to represent the variable values. For example, within the calculus of the effort value for the knowledge/design sub-section, this is defined as $\left(\boldsymbol{E}_{\boldsymbol{i}}\right)$, costs as $\left(\boldsymbol{c}_{\boldsymbol{i}}\right)$ and time as $\left(\boldsymbol{t}_{\boldsymbol{i}}\right)$; and similarly within the input/design sub-section; and so on and so forth for all other sub-sections. Shown in the PACTUM Model $^{\odot}$ diagram (figure 4), the two right angles of the triangle denote either the sub-section(s) functional $\operatorname{costs}\left(\boldsymbol{c}_{\boldsymbol{i}}\right)$ or the sub-section(s) functional time $\left(\boldsymbol{t}_{\boldsymbol{i}}\right)$ values found within the supply-chain parameters. Consequently, the hypotenuse of the triangle (noted as not being of significant numerical / financial value) does however, allow for a visual and mathematical calculation of effort $\left(\boldsymbol{E}_{i}\right)$ which provides the hypotenuse a value to significantly correlate to that of the values assigned to the costs and time of the sub-section functionalities.

Accordingly, the man-made index (shown in section 3.2.9.) the displayed list of variables relating to the main sub-sections of the supply-chain have been identified through the primary and secondary research. It should be noted that the variables within each of the eight indexed sub-sections, would inevitably be commensurate with organisational structure and specific supply-chain networks, yet there is sufficient flexibility to allow model adopters to enter their own differential financial and time frame calculations.

3.2.8. PACTUM Model ${ }^{\odot}$ sub-section index. In relation to figure 9, the index below describes the arbitrary values and supply-chain functions which assess the effort grading system. The index also indicates the main titles given to the individual sub-sections which have been divided by using the supply-chains dependent variables.

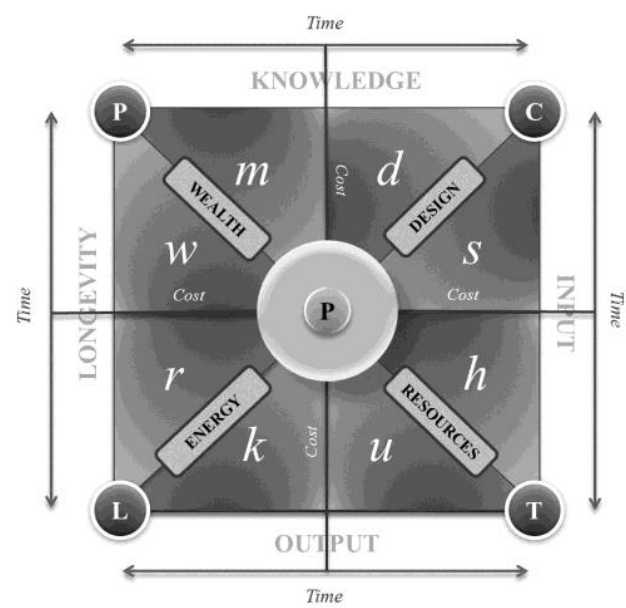

\subsubsection{Sub-section index.}

$\boldsymbol{m}=$ Primary management

$\boldsymbol{d}=$ Primary R $\& \mathrm{D}$

$\boldsymbol{s}=$ Primary pre-production

$\boldsymbol{h}=$ Secondary pre-production

$\boldsymbol{u}=$ Secondary mass production

$\boldsymbol{k}=$ Third party logistics

$\boldsymbol{r}=$ Primary logistics

$\boldsymbol{w}=$ Primary product sales data

$c=$ Costs

$\boldsymbol{t}=$ Time

$\boldsymbol{E}=$ Effort

Fig. 9. Illustration of how the PACTUM Model $^{\circledR}$ can visually show the highest effort values, assigned to the costs and time of each subsection of the supply-chain encountered.

3.2.10. PACTUM Model ${ }^{\odot}$ cost and time formulas. At this stage it is important to consider that the indexed subsections are a simplified representation of the supply-chains key performance indicators, and each index contains specific data relating to each supply-chain function; hence these will vary accordingly to the relevant situation attributed to them.

Using the model in figure 9, the PACTUM Model ${ }^{\odot}$ is able to assess the defined indexed sub-sections, either by individual products, specific product categories, product ranges and total product outputs of various organisations. Hence, shown in figure 9 and using the index (in section 3.2.9.) it should be noted that the axis of the triangle associated with costs $(\boldsymbol{c})$ is the actual monetary value $(£)$ which changes according to the assessment required. For example, an individual product category may have a value associated with the total category budget. Similarly the axis of the triangle associated with time $(\boldsymbol{t})$ is the actual time frame value which changes according to the assessment required for the period. For example, a total product range output may have a time value of 365 days; however this could be measured in hours, minutes or even seconds if necessary. Therefore, 
these values of costs and time are variable due to the nature of the predetermined product assessment and the nature of the organisation encountered and model use should be systematic and consistent.

Subsequently, the effort total $\left(\boldsymbol{E}_{\boldsymbol{T}}\right)$ calculus for the supply-chain is dependent on the differential variables attributed to each organisation assessed and is expressed in formula 5. It is worthy of pointing out however, that these sub-section indexed variables may require high levels of cost and time in order to perform the functions required by each sub-section depending on the type of product being developed and supply-chain networks used. Illustrated by figures $10 \& 11$, the graphical PACTUM $\mathrm{Model}^{\circ}$ simulations show how different product lifecycle practices can highlight variable degrees of high effort and low effort values, within each specific sub-section indexed.

$$
E_{T}=\sum_{i} E_{i}=\sum_{n} \frac{1}{\sqrt{c_{i}^{2}+t_{i}^{2}}}
$$

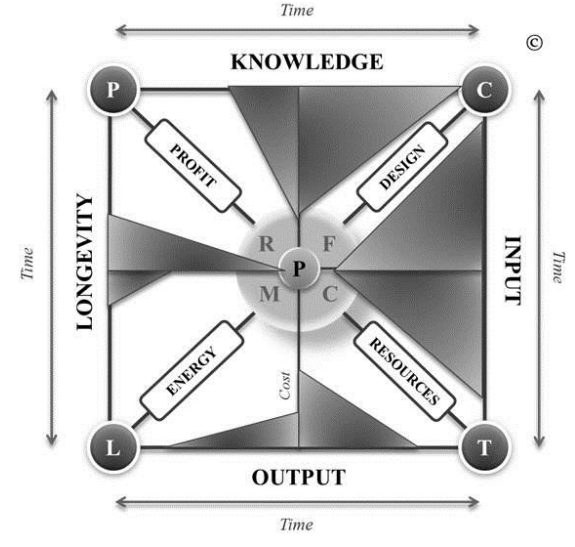

Fig. 10. Illustration and an example of how the PACTUM Model ${ }^{\odot}$ can visually show the effort values, of cost and time, aligned to each sub-sections of the supply-chain.

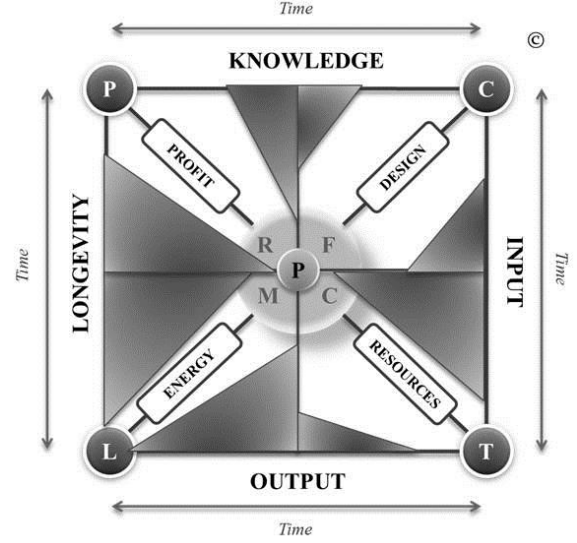

Fig. 11. Illustration and an example of how the PACTUM Model $^{\odot}$ can visually show the effort values, of cost and time, aligned to each sub-sections of the supply-chain.

\section{Conclusion \& Recommendations}

From the post-coding analysis conducted on the primary data sets, significant issues arose from a variety of different dependent and independent functional needs within the observed global supply-chain; especially when conducting the primary action and observational research into global product development lifecycle practices.

The methodical approach to model formulation outlined by Ref. 15 was found to give a clear starting point and a systematic approach to the steps needed for the development of such a complex synergy. Furthermore, their suggestion that statistical learning techniques are a valuable tool for detecting complex relationships and interaction variables was indeed helpful in the model theory, mathematics and simplification process of the supply-chain variables and functional properties. In line with this approach, the mathematical formula for calculating each sub-sections effort value was preliminarily devised and adapted using Pythagoras Theorem ${ }^{23}$.

The literature review into problem solving execution, specifically that of Six Sigma DMAIC (DefineMeasure-Analyse-Improve-Control) general methods for problem solving; which deserves acclaim for its strong emphasis on statistics, structural method capabilities and potential to break down problems into generic subtasks, was most insightful and beneficial to the problem of simplifying such complex supply-chain structures. DMAIC suggested approaches of definition stream and science research stream problem solving applications, delivered valuable accomplishments when facilitating the statistical modelling of cause-and-effect functions within the supply-chain construction. Concurrently, the use of DMAIC within applications of supply-chain management problem solving did indeed have a strong incorporation of domain knowledge along with fault knowledge elements $^{18}$; thus, domain knowledge diagnosis of the problem was fundamental in developing the PACTUM Model $^{\circ}$. Additionally, the accompanying methods of brainstorming, data mining, cause-and-effect diagrams and exploratory data analysis were imperative systems for evaluating the complex data sets researched, investigated and analysed. 
By highlighting the most significant core dependent product functions, dependent effort functions, dependent variables and independent variables found to be used within current supply-chain strategies; the PACTUM Model $^{\odot}$ represented by figure 4, allows potential model adopters to divide their differential organisational functions, practices, employment roles and overheads, into structured indexed sub-sections (considering their own specific cost and time values for each indexed sub-section). Adopters should allow the assumptions that their current practices in product lifecycle engagement; are required to posses systematically effective handling of the identified variables and functions; have inbuilt flexible working practices which allow the variable connections to be simultaneously inclusive and/or exclusive of each other; plus recognising that the supply-chain has neither a beginning nor an end point; whilst also appreciating that every connection made between the variables, has a positive or negative impact on the successional route taken during product lifecycle commitments.

It can be said therefore, that differential fashion supply-chains, whether local or global in their construction, are merely a series of processes defined by a single/multitude of human agreements which are then used to produce an artefact for a specified profitable reason; with the human functional capabilities being the subject of both the product and process success. Or simply, one needs to employ competent/skilled employees; define systematic critical paths; products and establish trustworthy networks to achieve an agreed output; so that the organisations involved attract and maintain a loyal consumer-based funding stream. Profit margins are the reasons for conducting such supply-chain behaviours; which could be measured and quantified within ranges of greed, power and/or necessity. These ranges are dependant on the individual human or collaborative human groups functional need/want levels. These ranging levels can then be physically represented by the very product types/quantities which society strives to develop, produce, sell, buy and use. These principal human functions of accumulating capital means by product development strategies, appears to specifically drive the fashion industry to continually reinvent the little black dress and for consumers to continually assume they require a new version. These capital drivers of consumption could be distinguishable perceived human functions, which can be attributed to human culture(s) and are possibly not inherent human functions, like those born from science or nature, but are learnt or nurtured human functions born from marketing and promotional activities. Ergo, significant research strategies into future supply-chain practices are needed to consider: How can we assimilate/disseminate information to a highly populated global society, with complex mixes of demographics, cultures, varying levels of education, tastes and desires, within a drastically diverse developing world environment; to enable the consideration of what the alternative principal/capital drivers of human functions should be; in order for the fashion industry, and other industries alike, to actively reduce product consumption; yet still deliver high levels of organisation and consumer aspiration? Plus, does an emerging globally social society even have the ability/desire to address what constitutes the mutually beneficial and morally acceptable levels of greed, power and necessity?

But that as it may, this research paper acknowledges that it's not in a league of accomplishment devised by some mathematicians, philosophers, rocket scientists, biologists, chemists or astrophysicists. Yet, there are beliefs that even small steps towards hybrid methodology use and contemporary analytical practices might produce alternative giant leaps forward in supply-chain management strategies, physical sciences, human knowledge and their future ascendants.

Consequently, although the PACTUM $\operatorname{Model}^{\circ}$ alone cannot conclusively answer such multiplex questions such as increasing fashion consumption, nor can it be considered a final fix to supply-chain management or human philosophy; it is able to allow new thought on the effectiveness of existing and future supply-chain engagements and their subsequent product lifecycle experiences and outputs.

Significantly, this new method for calculating and comprehending product lifecycle functional capabilities within global fashion supply-chains, described throughout this paper as the 'Product Analysis of Cost and Time Using Mathematical Modelling' method (abbreviated to PACTUM Model ${ }^{\circ}$, pactum being the Latin word for "pact" which constitutes a term used to describe an agreement between human functions; such as those now embedded within human philosophy and existing global fashion supply-chain networks) does nevertheless, allow a multitude of future research avenues which could provide accomplished academics and industry specialists the incentive to develop collaborative links in order to produce a computer generated version of the PACTUM Model $^{\odot}$ (Intellectual Property rights apply).

Conclusively, the discussed mathematical formulas will enable some established business leaders and academics to address the holistic nature of organisational variables, attributed to the effort values found within differential supply-chain environments and product development practices; to be calculated, analysed, evaluated, adapted, re-configured and critiqued in more depth than previously envisaged. 


\section{Acknowledgements}

Dr Leif Vogel

\section{References}

1. Tyler D, Heely J, Bhamra T., Supply chain influences on product development in fashion clothing, J. Fash. Mktg. \& Mgt. 10:316, 2006.

2. Hayes S, Jones N., Fast fashion: a financial snapshot, J. Fash. Mktg. \& Mgt. 10:282, 2006.

3. Caridi M, Perego A, Tumino A., Measuring supply chain visibility in the apparel industry, An Int. J. 20:25-6, 2013.

4. Lam J K C, Postle R., Textile and apparel supply chain management in Hong Kong, Int. J. Clthg. Sci. \& Tech. 18:266, 2006.

5. Trent R, Monczka R M., Understanding intergrated global courcing, Int. J. Phys. Dist. \& Logs. Mgt. 33:609-27, 2003.

6. Lee Y, Kincade D H., US apparel menufacturers' company characteristic differences based on SCM activities, J. Fash. Mktg. \& Mgt. 7:31-2, 2003.

7. Easters D J., Global communication part 2: The use of apparel product data management technology, Int. J. Fash. Des. Tech \& Edu. 5/1:135-43, 2011.

8. Mattila H, Kind R, Ojala N., Retail performance measures for seasonal fashion, J. Fash. Mktg. \& Mangt. 6:340-51, 2002.

9. Goworek H., An investigation into product development processes for UK fashion retailers, J. Fash. Mktg. \& Mgt. 14:649, 2010.

10. Assen M, Berg G, Pietersma P., Key Management Models, 2nd Edition, Prentice Hall, p.136-139, 2009.

11. Wigley S, Moore C M., The operationalisation of international fashion retailer success, J. Fash. Mktg. \& Mgt. 11:281-83, 2007.

12. Easters D J., Global communication part 1: The use of apparel CAD technology, Int. J. Fash. Des. Tech \&Edu. 5/2:45-54, 2011.

13. Kotabe M, Murray J Y., Global sourcing strategy and sustianable competative advantage, Indst. Mktg. Mgt. 33:7-14, 2004.

14. Rollins R P, Porter K, Little D., Modelling the changing apparel supply chain, Int J. Clthg. Sci. \& Tech.15:140-55, 2003

15. Wilson C, Wilson R., Mathematical sollutions for accelerated product development, Tex. Inst. J. 3:26-8, 2012.

16. Bryman A., Social Research Methods, 3rd Edition, NY: Oxford University Press Inc., p.1-689, 2008.

17. Saunders M, Lewis P, Thornhill A., Research Methods for Business Students, 5th Edition, Pearson Proffressional Ltd., p1-631 , 2009.

18. De Mast J, Lokkerbol J., An analysis of the Six Sigma DMAIC method from the perspective of problem solving, Int. J. Production Economics. 139:604-14, 2012.

19. Yeung J H Y, et al., Postponement strategy from a intergrated framework, Int. J. Physl. Dist. 37/4:33156, 2004.

20. Fisher M L., What is the Right Supply Chain for your product? Harvard Business Review (March/April):105-16, 1997.

21. Gereffi G., International trade and idustrial upgrading in the apparel commodity chain, J. Int. Ecom. 48/1:37-70, 1999.

22. Rice J B, Hoppe R M., Supply Chain versus Supply Chain: The hype and reality, Supply Chain Mang.t Review. (Sept-Oct):1-16, 2001.

23. Maor E., The Pythagorean Theory A, 4000 years, NJ: Princeton University Press. p.35, 2007. 